\title{
Screening of SARS-CoV-2 among homeless people, asylum-seekers and other people living in precarious conditions in Marseille, France, March-April 2020
}

\author{
a Aix-Marseille University, IRD, AP-HM, SSA, VITROME, Marseille, France \\ ' IHU-Méditerranée Infection, Marseille, France \\ ${ }^{\mathrm{c}}$ Family Medicine Department, Thai Binh University of Medicine and Pharmacy, Viet Nam \\ ' VITROME, Campus International IRD-UCAD de l'IRD, Dakar, Senegal \\ e Pneumology Department, Thai Binh University of Medicine and Pharmacy, Viet Nam \\ ${ }^{\mathrm{f}}$ Aix-Marseille University, IRD, AP-HM, SSA, MEPHI, Marseille, France
}

Tran Duc Anh Ly ${ }^{\mathrm{a}, \mathrm{b}}$, Nhu Ngoc Nguyen ${ }^{\mathrm{a}, \mathrm{b}}$, Van Thuan Hoang ${ }^{\mathrm{a}, \mathrm{b}, \mathrm{c}}$, Ndiaw Goumballa ${ }^{\mathrm{a}, \mathrm{d}}$, Meriem Louni $^{\mathrm{a}, \mathrm{b}}$, Naomie Canard ${ }^{\mathrm{a}, \mathrm{b}}$, Thi Loi Dao ${ }^{\mathrm{a}, \mathrm{b}, \mathrm{e}}$, Hacene Medkour ${ }^{\mathrm{b}, \mathrm{f}}$, Audrey Borg ${ }^{\mathrm{b}}$, Kevin Bardy ${ }^{\mathrm{b}}$, Véra Esteves-Vieira ${ }^{\mathrm{b}}$, Véronique Filosa ${ }^{\mathrm{b}}$, Bernard Davoust ${ }^{\mathrm{b}, \mathrm{f}}$, Oleg Mediannikov ${ }^{\mathrm{b}, \mathrm{f}}$, Pierre-Edouard Fournier ${ }^{\mathrm{a}, \mathrm{b}}$, Didier Raoult ${ }^{\mathrm{a}, \mathrm{b}, \mathrm{f}}$, Philippe Gautret ${ }^{\mathrm{a}, \mathrm{b}, *}$

\section{A R T I C L E I N F O}

\section{Article history:}

Received 7 December 2020

Accepted 5 February 2021

\section{Keywords:}

COVID-19

SARS-CoV-2

Homelessness

Asylum-seekers, precarious conditions

Real-time polymerase chain reaction

\begin{abstract}
A B S T R A C T
Background: Surveillance of severe acute respiratory syndrome coronavirus 2 (SARS-CoV-2) infection among sheltered homeless and other vulnerable people might provide the information needed to prevent its spread within accommodation centres.

Methods: Data were obtained from 698 participants in different accommodation centres (411 homeless individuals, 77 asylum-seekers, 58 other people living in precarious conditions and 152 employees working in these accommodation centres) who completed questionnaires and had nasal samples collected between 26 March and 17 April 2020. SARS-CoV-2 carriage was assessed by quantitative PCR. Results: We found a high acceptance rate (78.9\%) for testing. Overall, 49 people (7.0\%) were positive for SARS-CoV-2, including 37 homeless individuals (of 411, 9.0\%) and 12 employees (of $152,7.9 \%$ ). SARS-CoV2 positivity correlated with symptoms, although $51 \%$ of patients who tested positive did not report respiratory symptoms or fever. Among homeless people, being young (18-34 years) (odds ratio 3.83, 95\% confidence interval 1.47-10.0, $p=0.006$ ) and being housed in one specific shelter (odds ratio 9.13,95\% confidence interval 4.09-20.37, $p<0.001$ ) were independent factors associated with SARS-CoV-2 positivity (rates of $11.4 \%$ and $20.6 \%$, respectively).

Discussion: Symptom screening alone is insufficient to prevent SARS-CoV-2 transmission in vulnerable sheltered people. Systematic testing should be promoted.

(c) 2021 The Authors. Published by Elsevier Ltd on behalf of International Society for Infectious Diseases.

This is an open access article under the CC BY license (http://creativecommons.org/licenses/by/4.0/).
\end{abstract}

\section{Introduction}

Since March 2020, coronavirus disease 2019 (COVID-19), which is caused by severe acute respiratory syndrome coronavirus 2 (SARS-CoV-2), has spread to more than 200 countries and territories worldwide (Johns Hopkins Coronavirus Resource Center, 2020). Homeless people are a vulnerable group who may potentially be exposed to this infection and potentially have

\footnotetext{
* Corresponding author at: VITROME, Institut Hospitalo-Universitaire Méditerranée Infection, 19-21 Boulevard Jean Moulin, 13385 Marseille Cedex 05, France.

E-mail address: philippe.gautret@club-internet.fr (P. Gautret).
}

severer outcomes than the general population because of their poor living conditions, higher prevalence of comorbidities, and mental and physical conditions impaired by substance or alcohol abuse (Kar et al., 2020; Kirby, 2020; Lima et al., 2020; Neto et al., 2020; Tsai and Wilson, 2020) Crowded conditions in shelters without specific preventive measures could facilitate viral transmission (Peate, 2020; Wood et al., 2020). In an early study conducted between March and April 2020 in Hamilton, Canada, COVID-19 was diagnosed in $1 \%$ of sheltered homeless people and $5 \%$ of staff members (Bodkin et al., 2020). In several US cities, in the same period, 1192 residents and 313 staff members were tested in 19 homeless shelters, and high rates of SARS-CoV-2 carriage were observed in residents (25\%) and staff members (11\%) (Baggett et al., 
2020a; Mosites et al., 2020); furthermore, the prevalence was reported to be $9.7-15.5 \%$ among residents and $13.3-14.8 \%$ among staff members in three homeless shelters in Washington state (Tobolowsky et al., 2020) and 67.3\% among residents and $16.7 \%$ among staff members in one homeless shelter in San Francisco. (Imbert et al., 2020). In addition, 2.0\% of residents from 14 shelters in Washington state tested positive (Rogers et al., 2021), 11.9\% of residents from fives shelters in Rhode Island tested positive (Karb et al., 2020), $2.1 \%$ of residents from 24 shelters in Atlanta tested positive (Yoon et al., 2020) and 33.1\% of sheltered homeless and marginally housed people in Boston tested positive (Baggett et al., 2020b). This raised concerns that the virus may be widely transmitted within homeless shelters.

Over the past two decades, our institute has conducted a large number of surveys among homeless people in two shelters (A and B) in Marseille, France. We observed a high prevalence of respiratory symptoms and signs (Badiaga et al., 2009) and high carriage rates of both respiratory viruses (Thiberville et al., 2014) and bacteria (Ly et al., 2019), suggesting that SARS-CoV-2 infection might also be frequent in this population. On the basis of preliminary information that some homeless people from these two shelters exhibited COVID-19 symptoms, we organised a screening campaign in collaboration with the staff in charge of these shelters. We subsequently received other requests for screening from several accommodation centres specialising in housing vulnerable people. In this study, we present the results of SARS-CoV-2 screening campaigns conducted among sheltered homeless individuals in comparison with asylum-seekers, other people living in precarious conditions and employees working in the accommodation centres. We also investigated the role of potential risk factors for SARS-CoV-2 carriage among the homeless population.

\section{Methods and materials}

\section{Ethics}

Ethical approval was obtained from the Institutional Review Board and Ethics Committee of our institute (2020-015).

\section{Setting, study design and population}

A cross-sectional survey was conducted between 26 March and 17 April 2020 in different populations, including homeless people residing in four shelters (A-D) and four hotels (1-4) that were specifically used to house homeless people during the pandemic, other people living in precarious conditions (housed in residences $\alpha$ and $\beta$ ), asylum-seekers (housed in residence $\gamma$ ) and employees working in these accommodation centres. This represents a convenient sample because these residences requested testing. Follow-up was conducted in three shelters (A-C) until November 2020.

Homeless shelters A-C include emergency (overnight stay) units with a rapid turnover (7-14 nights), and special (permanent stay) units dedicated to high-risk sedentary homeless people characterised by a high level of poverty, poor hygiene, alcoholism, mental illness and chronic diseases. Shelters A and B are for men only, while shelter $C$ is for women only. Shelter D houses male and female homeless people and offers the possibility for them to keep their pets if needed. The characteristics of the facilities are described in Table 1 . All residents of homeless shelters were placed under strict lockdown from 17 March (defined as "CO"), in line with the whole French population, requiring all homeless people to stay in the shelter 24 hours a day. Homeless people were required not to leave the shelters for any reason (with rare exceptions). The residences provided all necessary items. A few individuals were 
newly admitted and all were tested for SARS-CoV-2 and isolated before the results were available. The population (male) of shelter A (initial group A) was subdivided into three groups by the staff of the facility to avoid overcrowding: (i) elderly people, those with reduced mobility and those needing medical care were kept in shelter A; (ii) people aged 18-45 years were progressively moved to hotel 1 from $\mathrm{C} 0$ to $\mathrm{C} 7$; (iii) people aged $30-80$ years were moved to hotel 2 from C7 to C14. Similarly, the population (female) of shelter C (initial group C) was subdivided into three groups: (i) elderly people, those with reduced mobility and those needing medical care were kept in shelter C; (ii) pregnant women and those with mental illness were moved to hotel 3 at C0; (iii) other residents were moved to hotel 4 at $\mathrm{C} 0$. All residents moved to hotels were kept under relatively strict lockdown from $\mathrm{C} 0$, with the exception of the day of transfer.

Residence $\alpha$ is dedicated to individuals characterised by a high level of poverty, poor hygiene, alcoholism, mental illness and chronic diseases, including drug addiction. Residence $\beta$ specialises in housing teenage mothers and their children. Residence $\gamma$ is dedicated to asylum-seekers, including family groups and single individuals. All three residences offer long-term housing, and all residents were kept under strict lockdown from $\mathrm{C} 0$.

These residences were located in different part of Marseille, far from each other.

Employees of the different facilities working in different sectors (management staff, social workers, nurses, cleaning staff, catering staff and security staff) returned to their homes on a daily basis after finishing work. Employees did not work in multiple facilities, with the exception of medical staff in shelters A and C, who cared for people in hotels 1 and 2 and in hotels 3 and 4, respectively.

\section{Screening for COVID-19}

Participants were encouraged by the management staff of the facilities to be tested and were then recruited on a voluntary basis.
They were systematically asked to provide basic demographic information (sex, age and country of origin), information on chronic conditions and information on any respiratory symptoms or fever in the 2 weeks before sampling. Body temperature was measured with a forehead infrared thermometer. We defined a fever as a measured temperature of $37.8^{\circ} \mathrm{C}$ or higher. Nasal samples were systematically collected on transport medium with use of Sigma Transwabs (Medical Wire, Corsham, UK). For self-sampling, participants were invited to insert the swab into their nostrils (about $2 \mathrm{~cm}$ ). If individuals were unable to perform self-sampling, trained investigators did the sampling. Specimens were immediately processed for SARS-CoV-2 PCR testing. Homeless peoples' pets were also tested with the approval of their owner, and their nasal swabs were collected by vets. The participants or medical staff were informed of the test result with a delay of $24 \mathrm{~h}$. Before testing, residents were told what would happen if the test result was positive. Residents who tested positive were moved to special facilities for COVID-19 homeless patient isolation or kept in a single room at residences with strict isolation measures for 14 days. Infected staff members were instructed to stay at home for 14 days.

\section{PCR assay}

Real-time reverse transcription PCR amplification was used to confirm the presence of SARS-CoV-2 RNA targeting the gene coding for the envelope (E) protein, as previously described (Amrane et al., 2020). Results were considered positive when the cycle threshold (Ct) value of real-time PCR was 35 or less.

\section{Statistical analysis}

Statistical analyses were performed with STATA 11.1 (StataCorp. LLC, College Station, TX, USA). Percentage differences were tested with Pearson's chi-square test or Fisher's exact test as appropriate. Means of quantitative data were compared with Student's $t$ test. A

Table 2

Numbers of individuals screened and results of severe acute respiratory syndrome coronavirus 2 (SARS-CoV-2) PCR detection according to housing structures.

\begin{tabular}{|c|c|c|c|c|c|c|c|c|c|c|c|}
\hline \multirow[t]{2}{*}{ Housing structure } & \multicolumn{3}{|c|}{$\begin{array}{c}\text { Number of people present at } \\
\text { time of enrolment }\end{array}$} & \multicolumn{4}{|c|}{ Number of people tested $(\%)^{1}$} & \multicolumn{4}{|c|}{$\begin{array}{l}\text { Numbers of people testing positive for } \\
\text { SARS-CoV-2 (\% of people tested) }\end{array}$} \\
\hline & Total & Residents & Employees & Total & Residents & Employees & $p$ & Total & Residents & Employees & $p$ \\
\hline Total & 885 & 716 & 169 & $698(78.9)$ & $\begin{array}{r}546 \\
(76.2)\end{array}$ & $152(90.0)$ & $<0.001$ & $49(7.0)$ & $37(6.8)$ & $12(7.9)$ & 0.77 \\
\hline Homeless shelter & 683 & 551 & 132 & $528(77.3)$ & $\begin{array}{r}411 \\
(746)\end{array}$ & $117(88.7)$ & $<0.001$ & $48(9.1)$ & $37(9.0)$ & $11(9.4)$ & 1.00 \\
\hline Shelter A & 121 & 86 & 35 & $78(64.5)$ & $54(62.8)$ & $24(68.6)$ & 0.7 & $13(16.7)$ & $10(18.5)$ & $3(12.5)$ & 0.7 \\
\hline Shelter B & 305 & 262 & 43 & $270(88.5)$ & $\begin{array}{r}227 \\
(86.6)\end{array}$ & $43(100)$ & 0.007 & $15(5.6)$ & $9(4.0)$ & $6(14.0)$ & 0.02 \\
\hline Shelter C & 48 & 19 & 29 & $40(83.3)$ & $14(73.7)$ & $26(89.7)$ & 0.23 & $2(5.0)$ & 0 & $2(7.7)$ & NA \\
\hline Shelter D ${ }^{2}$ & 36 & 27 & 9 & 33 (91.7) & $25(92.6)$ & $8(88.8)$ & 1.00 & 0 & 0 & 0 & NA \\
\hline Hotel 1 & 72 & 65 & 7 & $30(41.7)$ & $23(35.4)$ & $7(100)$ & 0.001 & $9(30.0)$ & $9(39.1)$ & 0 & 0.07 \\
\hline Hotel 2 & 75 & 70 & 5 & $54(72)$ & $49(70)$ & $5(100)$ & 0.3 & $7(13.0)$ & $7(14.3)$ & 0 & 0.48 \\
\hline Hotel 3 & 14 & 13 & 1 & $12(85.7)$ & $11(84.6)$ & $1(100)$ & 1.00 & $1(8.3)$ & $1(9.1)$ & 0 & NA \\
\hline Hotel 4 & 12 & 9 & 3 & $11(91.7)$ & $8(88.9)$ & $3(100)$ & 1.00 & $1(9.1)$ & $1(12.5)$ & 0 & NA \\
\hline $\begin{array}{l}\text { Residence for } \\
\text { specific } \\
\text { populations living } \\
\text { in precarious } \\
\text { conditions }\end{array}$ & 81 & 63 & 18 & $75(92.6)$ & $58(92.1)$ & $17(94.4)$ & 1.00 & 0 & 0 & 0 & NA \\
\hline Residence $\alpha$ & 28 & 23 & 5 & $28(100)$ & $23(100)$ & $5(100)$ & 1.00 & 0 & 0 & 0 & NA \\
\hline Residence $\beta$ & 53 & 40 & 13 & $47(88.6)$ & $35(87.5)$ & $12(92.3)$ & 1.00 & 0 & 0 & 0 & NA \\
\hline $\begin{array}{l}\text { Residence for } \\
\text { asylum-seekers } \\
\quad \text { Residence } \gamma\end{array}$ & 121 & 102 & 19 & $95(78.5)$ & $77(75.5)$ & $18(94.7)$ & 0.07 & $1(1.1)$ & 0 & $1(5.6)$ & NA \\
\hline
\end{tabular}

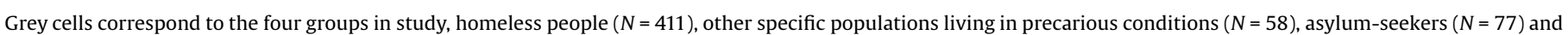
employees $(N=152)$, and the SARS-CoV-2 prevalence in each group.

NA, not applicable.

${ }^{1}$ Acceptance rate.

${ }^{2}$ Two dogs belonging to two different homeless people in shelter $\mathrm{D}$ were tested and tested negative. 
$p$ value less than 0.05 was considered statistically significant. A separate multivariate logistical regression analysis was used to identify independent risk factors for SARS-CoV-2 carriage prevalence among all individuals and in selected groups (when positive cases were found). The results are presented as percentages and odd ratios (ORs) with the $95 \%$ confidence interval (CI). The initial model included variables with $p<0.2$. The stepwise regression procedure and likelihood-ratio tests were applied to determine the final model.

\section{Results}

\section{Participant characteristics}

Overall, 885 individuals were present in the various facilities at the time of enrolment, including 716 residents and 169 employees (Table 2). A total of 698 individuals (78.9\%) agreed to be tested, including 411 homeless people (58.9\%), 58 non-homeless people living in precarious conditions (8.3\%), 77 asylum-seekers (11.0\%), and 152 employees (21.8\%). Overall, 38.7\% were enrolled before C14, $45.9 \%$ between C14 and C20 and $15.4 \%$ at C21 or later. The overall acceptance rate for SARS-CoV-2 testing varied significantly according to the housing facility, ranging from $41.7 \%$ to $91.7 \%$. The overall acceptance rate among homeless individuals was $74.6 \%$ and was significantly lower than that of employees working in the homeless centres $(88.7 \%, p \leq 0.001)$ (Table 2$)$. The acceptance rate among people housed in other facilities ranged from $75.5 \%$ to $100 \%$ and tended to be lower than that of employees in these facilities (Table 2).

The socio-demographic characteristics of the different populations are presented in Table 3. The male-to-female ratio was 3:1 and the median age was 35.0 years (range from 0 to 91 years), with significant variations among different populations. A male predominance was observed among homeless people and asylum-seekers. Children aged 15 years or younger accounted for $7.5 \%$ of all residents. Two-thirds of individuals were migrants. A predominance of African origin was found among homeless individuals, while other people living in precarious conditions and employees were more likely to be European. Most asylumseekers had African or Asian origin. There were only four pregnant women (between 26 and 36 weeks of pregnancy), all housed in hotel 3 .

\section{Clinical symptoms and SARS-CoV-2 detection}

Among all the participants, $22.1 \%$ reported at least one respiratory symptom or fever, with significant variations among different populations. The highest prevalence was observed among employees (25.7\%) and homeless people (24.3\%). A cough was the most commonly reported symptom (32.7\%), followed by rhinorrhoea (20.4\%), dyspnoea (12.2\%) and fever (12.2\%). No deaths were reported during the study period.

In total, 49 participants (7.0\%) tested positive for SARS-CoV-2, including 37 homeless people (of 441, 9.0\%) and 12 employees (of $152,7.9 \%$, including seven security staff from shelters A, B and C and residence $\gamma$, four nurses from shelter $B$ and one management staff member from shelter C). Only two female homeless people tested positive, including one woman who was 36 weeks' pregnant and who frequently attended the hospital during the lockdown and one person with mental illness living at hotel 3 who did not comply with lockdown measures, frequently leaving the hotel.

Two dogs belonging to two different homeless people in shelter $D$ tested negative. With regard to the housing facilities, the highest SARS-CoV-2 positivity rates were observed in homeless people in hotel 1 (39.1\%), in shelter A (18.5\%) and in hotel 2 (14.3\%). Among employees, the highest positivity rates were in those working at homeless shelter B (14\%) and homeless shelter A (12.5\%).

Of the 49 SARS-CoV-2-positive participants, $51.0 \%$ were asymptomatic. Participants who tested positive were more likely to be symptomatic compared with participants who tested negative (OR 3.8, 95\% CI 2.1-6.9, $p<0.001$ ). There was no significant difference in PCR Ct values between asymptomatic individuals (mean Ct 26.9, standard deviation 5.0) and symptomatic individuals (Ct $25.7 \pm 5.4, p=0.43$ ). The overall proportion of

Table 3

Characteristics of different populations studied.

\begin{tabular}{|c|c|c|c|c|c|c|c|}
\hline Characteristic & & $\begin{array}{l}\text { Total screened } \\
(N=698)\end{array}$ & $\begin{array}{l}\text { Homeless people } \\
(N=411)\end{array}$ & $\begin{array}{l}\text { Other specific } \\
\text { populations in } \\
\text { precarious } \\
\text { conditions }(N=58)\end{array}$ & $\begin{array}{l}\text { Asylum seekers } \\
(N=77)\end{array}$ & $\begin{array}{l}\text { Employees } \\
(N=152)\end{array}$ & $p^{\mathrm{d}}$ \\
\hline \multirow[t]{3}{*}{ Time of screening } & Before $\mathrm{C} 14, n(\%)^{\mathrm{e}}$ & $270(38.7)$ & $227(55.2)$ & $0(0)$ & $0(0)$ & $43(28.3)$ & $<0.001$ \\
\hline & From $\mathrm{C} 14$ to $\mathrm{C} 20, n(\%)$ & $320(45.9)$ & $159(38.7)$ & $0(0)$ & $77(100)$ & $84(55.3)$ & \\
\hline & At C21 and after, $n(\%)$ & $108(15.4)$ & $25(6.1)$ & $58(100)$ & $0(0)$ & $25(16.4)$ & \\
\hline \multirow[t]{2}{*}{$\operatorname{Sex}^{\mathrm{a}}$} & Male, $n(\%)$ & $529(75.8)$ & $369(89.8)$ & $25(43.1)$ & $50(64.9)$ & 85 (55.9) & $<0.001$ \\
\hline & Female, $n(\%)$ & $169(24.2)$ & $42(10.2)$ & $33(56.9)$ & $27(35.1)$ & $67(44.1)$ & \\
\hline \multirow[t]{4}{*}{ Age (years) } & Range (min-max) & $0-91$ & $18-91$ & $0-86$ & $0-67$ & $21-77$ & \\
\hline & Mean \pm SD & $37.4 \pm 16.9$ & $40.4 \pm 15.6$ & $25.0 \pm 24.0$ & $21.6 \pm 13.6$ & $41.9 \pm 11.1$ & $<0.001$ \\
\hline & Median, interquartile range & $35.0,26-49$ & $37.0,28-52$ & $19.0,2-49$ & $24.0,10-31$ & $41.5,33-50$ & \\
\hline & Children $\leq 15$ years, $n(\%)^{\mathrm{b}}$ & $41(7.5)$ & $0(0)$ & $19(32.8)$ & $22(28.6)$ & NA & $<0.001$ \\
\hline \multirow[t]{3}{*}{ Birthplace } & Europe, $n(\%)$ & $267(38.3)$ & $99(24.1)$ & $45(77.6)$ & $12(15.6)$ & $111(73.0)$ & $<0.001$ \\
\hline & Africa, $n(\%)$ & $351(50.3)$ & $269(65.5)$ & $11(19.0)$ & $32(41.6)$ & 39 (25.7) & \\
\hline & Asia, $n(\%)$ & $80(11.5)$ & $43(10.5)$ & $2(3.4)$ & $33(42.9)$ & $2(1.3)$ & \\
\hline \multicolumn{2}{|c|}{ Pregnant women $n / N(\%)^{\mathrm{c}}$} & $4 / 150(2.7)$ & $4 / 42(9.5)$ & $0 / 25(0)$ & $0 / 16(0)$ & $0 / 67(0)$ & 0.002 \\
\hline \multirow{6}{*}{$\begin{array}{l}\text { Presence of } \\
\text { respiratory } \\
\text { symptom and } \\
\text { fever }\end{array}$} & At least one symptom, $n(\%)$ & $154(22.1)$ & $100(24.3)$ & $10(17.2)$ & $5(6.5)$ & $39(25.7)$ & 0.003 \\
\hline & Cough, $n(\%)$ & $85(12.2)$ & $55(13.4)$ & $7(12.1)$ & $1(1.3)$ & $22(14.5)$ & 0.02 \\
\hline & Rhinorrhoea, $n(\%)$ & $64(9.2)$ & 49 (11.9) & $1(1.7)$ & $0(0)$ & $14(9.2)$ & 0.002 \\
\hline & Dyspnoea, $n(\%)$ & $42(6.0)$ & $27(6.6)$ & $2(3.4)$ & $2(2.6)$ & $11(7.2)$ & 0.41 \\
\hline & Sore throat, $n(\%)$ & $37(5.3)$ & $23(5.6)$ & $2(3.4)$ & $0(0)$ & $12(7.9)$ & 0.08 \\
\hline & Fever, $n(\%)$ & $19(2.7)$ & $10(2.4)$ & $1(1.7)$ & $2(2.6)$ & $6(3.9)$ & 0.75 \\
\hline
\end{tabular}

NA, not applicable; SD, standard deviation.

a Number of individuals for whom data were available.

b Of 546 residents.

c Of 150 females aged 15 years or older.

d Comparison among the four groups.

e C14 refers to day 14 of lockdown. 
asymptomatic carriers among all individuals tested was $3.6 \%$ and that of symptomatic carriers was 3.4\%.

Table 3 shows SARS-CoV-2 positivity rates among homeless people according to the time of screening, demographics and housing facility obtained by univariate analysis. No significant differences were observed according to sex and country of origin regarding SARS-CoV-2 positivity rates. Screening between C14 and C20 and screening in the group A population (shelter $A$ and hotels to which people from shelter $A$ were moved) resulted in a significantly higher proportion of participants with positive PCR test results as compared with screening before $\mathrm{C} 14$ or screening in other homeless facilities. In addition, being young (18-34 years) was associated with an increased likelihood of virus detection. Cough, rhinorrhoea and fever were associated with SARS-CoV-2 carriage. From multivariate analysis (Table 4), being young (OR $3.83,95 \% \mathrm{CI} 1.47-10.0, p=0.006$ ) and screening conducted in the group A population (OR 9.13, 95\% CI 4.09-20.37, $p<0.001$ ) remained significantly associated with a higher likelihood of SARSCoV-2 detection.

\section{Measures to mitigate the risk of transmission and follow-up}

Measures to mitigate the risk of transmission included staying in the housing facility, avoiding gatherings of people (including by moving individuals from shelters to hotels), wearing a mask, keeping distance from others, washing hands with soap and water frequently and for at least 20 seconds, practising cough etiquette, and avoiding touching the eyes, nose or mouth with unwashed hands. Follow-up conducted in shelters A, B and $\mathrm{C}$ resulted in a strong decrease of PCR positivity rates, with $1.1 \%$ of residents of shelter A and $0.4 \%$ residents of shelter B testing positive in September and November, respectively while no resident of shelter $\mathrm{C}$ tested positive in October (Figure 1).

\section{Discussion}

To our knowledge, this is the only study addressing SARS-CoV-2 carriage among different precarious populations including homeless adults but also children and other hard-to-reach populations during the COVID-19 outbreak in France. In Marseille, the first case of COVID-19 in the general population was diagnosed on 3 March 2020, and the epidemic peaked during the first week of April and remained active until the end of April (https://www.mediterraneeinfection.com/covid-19/). The strength of our study is its large population size, with a high acceptance rate (78.9\%) for testing, particularly among individuals living in precarious conditions (92.1\%), suggesting that this population is concerned about the disease.

We found an overall SARS-CoV-2 positivity rate of $7.0 \%$, with most infected individuals among homeless people and employees working in homeless facilities, while no cases were found in asylum-seekers and in other people also living in precarious conditions. Detection of SARS-CoV-2 correlated with symptoms, although many patients who tested positive did not report any respiratory symptoms or fever at the time of sampling. It cannot be excluded that some of them were actually presymptomatic. The high rate of asymptomatic SARS-CoV-2 carriers is in line with studies conducted in homeless shelters in the USA (Baggett et al., 2020a; Karb et al., 2020; Rogers et al., 2021). Asymptomatic and presymptomatic transmission may therefore be the predominant SARS-CoV-2 transmission mode in shelters. As a consequence, symptom-guided screening in this setting is not an effective strategy. Given that homeless people and professionals in contact with homeless people are at a high risk of COVID-19, these populations should benefit from screening campaigns, and specific measures aimed at mitigating the risks of transmission of the disease, including personal protective measures, within these populations and to the overall population should be implemented.

Among the populations of the four homeless shelters (A-D) that were screened, the highest prevalence was observed in the population initially housed in shelter A. This may have resulted from the higher number of individuals per room in this shelter, as compared with the other shelters, which may have encouraged transmission of the virus. Sleeping in shared dormitories and use of shared bathrooms, toilets and kitchens make the implementation of social distancing measures in the context of homeless shelters particularly challenging. Being young (18-34 years) was an independent factor associated with SARS-CoV-2 detection in the homeless group, which may be due to a higher propensity for younger homeless people to develop social interactions within the shelters and hotels as compared with people aged 50 years or older.

Measures that were undertaken by shelter staff members to mitigate the risk of transmission were effective in reducing the numbers of cases among residents, with only a slight increase in the number of cases observed in shelter B during the second epidemic in Marseille.

This work has some limitations. Our study population was not randomly and homogenously recruited. Participants' medical

Table 4

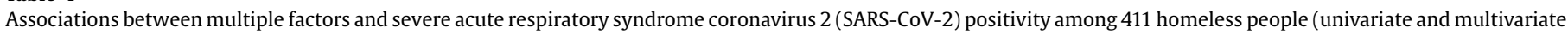
analysis).

\begin{tabular}{|c|c|c|c|c|c|c|c|}
\hline Characteristic & & Positive $(N=37)$ & Negative $(N=374)$ & $\begin{array}{l}\text { Univariate } \\
\text { OR }(95 \% \mathrm{CI})\end{array}$ & $p$ & $\begin{array}{l}\text { Multivariate } \\
\text { aOR }(95 \% \mathrm{CI})\end{array}$ & $p$ \\
\hline \multirow[t]{3}{*}{ Time of screening } & Before $\mathrm{C} 14, n(\%)^{\mathrm{b}}$ & $9(4.0)$ & $218(96.0)$ & Reference & & & \\
\hline & From $\mathrm{C} 14$ to $\mathrm{C} 20, n(\%)$ & $28(17.6)$ & $131(82.4)$ & $5.17(2.36-11.31)$ & $<\mathbf{0 . 0 0 1}$ & & \\
\hline & At C21 and later, $n(\%)$ & $0(0)$ & $25(100)$ & NA & 0.6 & & \\
\hline \multirow[t]{2}{*}{ Sex } & Male, $n(\%)$ & $35(9.5)$ & $334(90.5)$ & Reference & & & \\
\hline & Female, $n(\%)$ & $2(4.7)$ & $40(95.2)$ & $1.56(0.48-9.04)$ & 0.32 & & \\
\hline \multirow[t]{3}{*}{ Age (years) } & $\geq 50$ & $7(6.2)$ & $105(93.8)$ & Reference & & Reference & \\
\hline & $35-49$ & $9(8.3)$ & $100(91.7)$ & $1.34(0.48-3.76)$ & 0.56 & & \\
\hline & $18-34$ & $20(11.4)$ & $156(88.6)$ & $1.92(0.78-4.7)$ & 0.15 & $3.83(1.47-10.0)$ & 0.006 \\
\hline \multirow[t]{3}{*}{ Birthplace } & Europe, $n(\%)$ & $6(6.0)$ & $93(94.0)$ & Reference & & & \\
\hline & Africa, $n(\%)$ & $27(10.0)$ & $242(90.0)$ & $1.72(0.69-4.32)$ & 0.24 & & \\
\hline & Asia, $n(\%)$ & $4(9.3)$ & $39(90.7)$ & $1.58(0.42-5.94)$ & 0.49 & & \\
\hline \multirow[t]{2}{*}{ Housing facility ${ }^{\mathrm{a}}$} & Other homeless facilities, $n(\%)$ & $11(3.9)$ & $274(96.1)$ & Reference & & Reference & \\
\hline & Group A, $n(\%)$ & $26(20.6)$ & $100(79.4)$ & $6.47(3.1-13.6)$ & $<\mathbf{0 . 0 0 1}$ & $9.13(4.09-20.37)$ & $<0.001$ \\
\hline
\end{tabular}

aOR, adjusted odds ratio; $\mathrm{CI}$, confidence interval; NA, not applicable; OR, odds ratio.

Bold indicates the variables used in initial multivariate mode.

a Group A includes shelter A and hotels 1 and 2. Other homeless facilities include shelters B, C and D and hotels 3 and 4.

b C14 means day 14 of lockdown. 


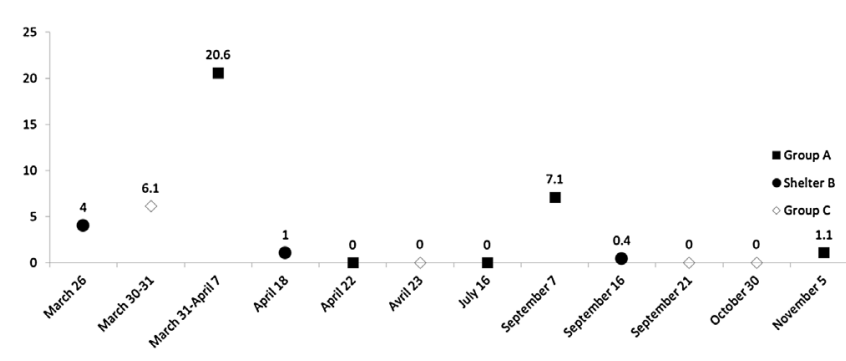

Figure 1. Positivity rates (\%) of severe acute respiratory syndrome coronavirus 2 (SARS-CoV-2) PCR screening campaigns in residents of three homeless shelters (A$C$ ) in Marseille in 2020. Group A includes shelter $A$ and hotels 1 and 2, and group $C$ includes shelter $C$ and hotels 3 and 4 (administered during the lockdown from 26 March to 5 November 2020).

histories and use of individual preventive measures were not documented. Individuals were not asked about anosmia and ageusia. No information was available regarding possible interactions of populations at other facilities (soup kitchens and day shelters) before lockdown. Notwithstanding these limitations, our data provide novel insight into the epidemiology of SARS-CoV-2 among different vulnerable urban populations. The survey also reveals the role of shared housing in relation to viral transmission within accommodation centres.

\section{Funding}

This work was supported by the French Government under the "Investments for the Future" programme managed by the National Agency for Research (ANR), Méditerranée-Infection 10-IAHU-03, and was also supported by Région Provence-Alpes-Côte d'Azur. This work received financial support from the Fondation Méditerranée Infection.

\section{Acknowledgements}

We are grateful to our colleagues for their help with statistical analysis and collection of samples and for technical assistance.

\section{References}

Amrane S, Tissot-Dupont H, Doudier B, Eldin C, Hocquart M, Mailhe M, et al. Rapid viral diagnosis and ambulatory management of suspected COVID-19 cases presenting at the infectious diseases referral hospital in Marseille, France, -
January 31st to March 1st, 2020: a respiratory virus snapshot. Travel Med Infect Dis 2020;36:101632.

Badiaga S, Richet H, Azas P, Zandotti C, Rey F, Charrel R, et al. Contribution of a shelter-based survey for screening respiratory diseases in the homeless. Eur J Public Health 2009; 19:157e60.

Baggett TP, Keyes H, Sporn N, Gaeta JM. Prevalence of SARS-CoV-2 infection in residents of a large homeless shelter in Boston. JAMA 2020a;323(21):2191-2.

Baggett TP, Racine MW, Lewis E, De Las Nueces D, O'Connell JJ, Bock B, et al. Addressing COVID-19 among people experiencing homelessness: description, adaptation, and early findings of a multiagency response in Boston. Public Health Rep 2020b;135(4):435-41.

Bodkin C, Mokashi V, Beal K, Wiwcharuk J, Lennox R, Guenter D, Smieja M, O'Shea T. Pandemic planning in homeless shelters: a pilot study of a COVID-19 testing and support program to mitigate the risk of COVID-19 outbreaks in congregate settings. Clin Infect Dis 2020; doi:http://dx.doi.org/10.1093/cid/ciaa743.

Imbert E, Kinley PM, Scarborough A, Cawley C, Sankaran M, Cox SN, et al. Coronavirus disease 2019 (COVID-19) outbreak in a San Francisco homeless shelter. Clin Infect Dis 2020;, doi:http://dx.doi.org/10.1093/cid/ciaa1071.

Johns Hopkins Coronavirus Resource Center. COVID-19 cases by county. 2020. . (accessed 29 April 2020 https://coronavirus.jhu.edu/map.html.

Kar SK, Arafat SMY, Marthoenis M, Kabir R. Homeless mentally ill people and COVID19 pandemic: the two-way sword for LMICs. Asian J Psychiatr 2020;51:102067.

Karb R, Samuels E, Vanjani R, Trimbur C, Napoli A. Homeless shelter characteristics and prevalence of SARS-CoV-2. West J Emerg Med. 2020;21(5):1048-53.

Kirby T. Efforts escalate to protect homeless people from COVID-19 in UK. Lancet Respir Med 2020;8(5):447-9.

Lima NNR, de Souza RI, Feitosa PWG, Moreira JLS, da Silva CGL, Neto MLR. People experiencing homelessness: their potential exposure to COVID-19. Psychiatry Res 2020;288:112945.

Ly TDA, Edouard S, Badiaga S, Tissot-Dupont H, Hoang VT, Pommier de Santi V, et al. Epidemiology of respiratory pathogen carriage in the homeless population within two shelters in Marseille, France, 2015-2017: cross sectional 1-day surveys. Clin Microbiol Infect 2019;25(2):249.e1-6.

Mosites E, Parker EM, Clarke KEN, Gaeta JM, Baggett TP, Imbert E, et al. Assessment of SARS-CoV-2 infection prevalence in homeless shelters - four U.S. cities, March 27-April 15, 2020. MMWR Morb Mortal Wkly Rep 2020;69(17):521-2.

Neto MLR, de Souza RI, Quezado RMM, Mendonça ECS, de Araújo TI, Luz DCRP, et al. When basic supplies are missing, what to do? Specific demands of the local street population in times of coronavirus - a concern of social psychiatry. Psychiatry Res 2020;288:112939.

Peate I. Self-isolation and the homeless population. Br J Nurs 2020;29(7):387.

Rogers JH, Link AC, McCulloch D, Brandstetter E, Newman KL, Jackson ML, et al. Characteristics of COVID-19 in homeless shelters: a community-based surveillance study. Ann Intern Med 2021;174(1):42-9.

Thiberville S, Salez N, Benkouiten S, Badiaga S, Charrel R, Brouqui P. Respiratory viruses within homeless shelters in Marseille, France. BMC Res Notes 2014;7:81.

Tobolowsky FA, Gonzales E, Self JL, Rao CY, Keating R, Marx GE, et al. COVID-19 outbreak among three affiliated homeless service sites - King County, Washington, 2020. MMWR Morb Mortal Wkly Rep 2020;69(17):523-6.

Tsai J, Wilson M. COVID-19: a potential public health problem for homeless populations. Lancet Public Health 2020;5(4):e186-7.

Wood LJ, Davies AP, Khan Z. COVID-19 precautions: easier said than done when patients are homeless. Med J Aust 2020;212(8) 384-384.e1.

Yoon JC, Montgomery MP, Buff AM, Boyd AT, Jamison C, Hernandez A, et al. COVID19 prevalence among people experiencing homelessness and homelessness service staff during early community transmission in Atlanta, Georgia, AprilMay 2020. Clin Infect Dis 2020;, doi:http://dx.doi.org/10.1093/cid/ciaa1340. 